IdeAs

Idées d'Amériques

$8 \mid 2016$

Ressources minières dans les Amériques: Mutations d'un continent

\title{
Donald Trump à la Maison Blanche : l'improbable vérité
}

\section{Vincent Michelot}

\section{(2) OpenEdition \\ Journals}

Édition électronique

URL : https://journals.openedition.org/ideas/1686

DOI : $10.4000 /$ ideas. 1686

ISSN : 1950-5701

Éditeur

Institut des Amériques

Référence électronique

Vincent Michelot, «Donald Trump à la Maison Blanche : l'improbable vérité », IdeAs [En ligne], 8| 2016, mis en ligne le 16 décembre 2016, consulté le 18 octobre 2022. URL : http://journals.openedition.org/ ideas/1686; DOI : https://doi.org/10.4000/ideas.1686

Ce document a été généré automatiquement le 18 octobre 2022.

\section{(c)}

Creative Commons - Attribution - Pas d'Utilisation Commerciale - Pas de Modification 4.0 International - CC BY-NC-ND 4.0

https://creativecommons.org/licenses/by-nc-nd/4.0/ 


\title{
Donald Trump à la Maison Blanche : l'improbable vérité
}

\author{
Vincent Michelot
}

1 Le 20 janvier 2017 Donald Trump prêtera serment et deviendra le $45^{\text {ème }}$ président des États-Unis. Le 16 juin 2015, lorsqu'il annonce sa candidature, aucun observateur avisé du politique américain ne le prend au sérieux et la question est en fait de savoir à quel stade de la campagne il jettera l'éponge et retournera à ses activités médiatiques et au monde des affaires. Moins de 17 mois plus tard il remporte une victoire ambigüe mais réelle face à Hillary Clinton au terme d'une campagne qui s'est presque entièrement déroulée autour de sa personnalité, de son aptitude à exercer la fonction présidentielle, de ses déclarations fracassantes ou provocantes, de ses frasques aussi. La principale question qui se pose aux Américains se réduit à un très simple : pour obtenir le changement, peut-on prendre le risque d'élire Trump ? Hillary Clinton répète à longueur de meetings que ce risque ne peut pas être pris, tant et si bien qu'elle oubliait qu'elle avait un programme et qu'elle se présentait pour le mettre en œuvre. Le candidat républicain, quant à lui, se présente à chaque occasion comme un puissant agent de changement de la langue, des thèmes et des codes du politique américain. Il minimise aussi le risque en insistant sur le parallèle entre la fonction présidentielle et celle de chef d'entreprise. En chemin, beaucoup de paradigmes de la science électorale ont été battus en brèche. L'élection du 8 novembre fut donc un double référendum, contre Hillary Clinton, pour Donald Trump. Désormais le magnat de l'immobilier doit gouverner, avec les contraintes partisanes et institutionnelles qui sont celles de la présidence américaine. Le pivot s'avère un exercice périlleux.

2 Ce dossier «Éclairages " se construit donc naturellement d'abord par un retour de Gilles Biassette sur ce que fut ce défi de couvrir cette campagne pour les journalistes. Il se prolonge par un texte d'Alix Meyer sur l'équilibre que pourra trouver Donald Trump avec la majorité républicaine au Congrès, à la suite d'élections dans les deux chambres qui ont été un peu passées sous silence mais qui n'en possèdent pas moins une importance capitale dans la construction du mandat du nouveau président. Vincent 
Michelot conclut sur les paradoxes d'une élection qui semble donner tous les pouvoirs à Donald Trump et qui pourtant recèle des fragilités et des incertitudes.

\section{AUTEUR}

\section{VINCENT MICHELOT}

Vincent Michelot est professeur des universités à Sciences Po Lyon où il enseigne la politique américaine. Spécialiste des élections et des rapports entre les pouvoirs de l'État aux Etats-Unis, il est l'auteur de Kennedy (Paris, Gallimard, 2013). vincent.michelot@sciencespo-lyon.fr 